ARTIG0

Recebido em: 19/07/2016

Aceito em: $17 / 05 / 2017$

\title{
Empoderamento e protagonismo social no setor de referência de bibliotecas universitárias
}

\author{
Empowerment and social leadership in the reference sector of university \\ libraries
}

\author{
Maria Giovanna Guedes FARIAS (mgiovannaguedes@gmail.com)* \\ Daysene de Araujo COSTA (dayse.araujo2015@hotmail.com)** \\ * Professora do Departamento de Ciência da Informação; Programa de Pós-Graduação em \\ Ciência da Informação - UFC. \\ ** Graduanda do curso de Biblioteconomia - UFC; Bolsista de Iniciação Científica PIBIC/UFC.
}

\begin{abstract}
Resumo
Apresenta resultados de pesquisa realizada com bibliotecários que atuam no setor de referência de bibliotecas universitárias. Objetiva analisar se esses profissionais apresentam indícios de empoderamento e estágios do protagonismo social no seu labor, mecanismos que podem colaborar para o desenvolvimento de estratégias que levem o bibliotecário a uma maior participação nas questões sociais, relativas à profissão, interação e comunicação com os usuários. Para tal, utilizou-se como metodologia a abordagem qualitativa, o método de pesquisa participante, questionários e entrevista para coleta de dados, os quais foram analisados pela técnica de análise de conteúdo. Os resultados demonstram que há nos sujeitos da pesquisa indícios do empoderamento e do protagonismo social nas ações no setor de referência junto aos usuários, a exemplo de: analisar a questão de pesquisa inicial do usuário, visando inserir de dados à pergunta e sugerindo aos usuários informações adicionais resultantes das pesquisas. Conclui que o bibliotecário ao se empoderar das informações que necessita, pode alcançar estágios do protagonismo social, como o estágio do trabalho, se tornando um agente transformador da realidade profissional em que atua, incentivando os usuários a se tornarem autônomos no acesso e uso da informação, reconhecendo o valor desta para sua formação.
\end{abstract}

Palavras-chave: Empoderamento. Protagonismo social. Bibliotecários. Setor de referência. Bibliotecas universitárias.

\begin{abstract}
Presents search results conducted with librarians who work in the reference section of university libraries. It aims to analyze whether these professionals have empowerment signs and stages of social involvement in their work, mechanisms that may contribute to the development of strategies that take the librarian to greater participation in social issues related to the profession, interaction and communication with users. To this end, it was used as methodology the qualitative approach, the participant survey method, questionnaires and interviews to collect data, which were analyzed using content analysis. The results show that there is in the subject of research evidence of empowerment and social role in the actions in the reference sector with users, like: examine the issue of the user's initial research, aiming to enter data to the question and suggesting users additional information resulting from the research. It concludes that the librarian when empower the information you need, you can reach stages of social leadership, and the status of the work, becoming a transforming agent of the professional reality in which it operates, encouraging users to become autonomous in access and use of information recognizing the value of this for their training.
\end{abstract}

Keywords: Empowerment. Social protagonism. Librarians. Reference sector. University libraries.

v. 22, n. 50, 2017. p. $1-14$

ISSN 1518-2924

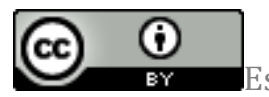

Esta obra está licenciada sob uma Licença Creative Commons 


\section{INTRODUÇÃo}

As mudanças sociais, políticas e econômicas que ocorrem na sociedade vêm trazendo rupturas comportamentais, as quais impactam na forma em que o indivíduo se relaciona com o outro, com a sociedade e consigo mesmo. Embora estas rupturas nem sempre sejam percebidas pelos que estão envolvidos nessa dinâmica, há sempre a possibilidade de trazerem inúmeros benefícios.

Tais mudanças se constituem em conquistas de uma nova forma de poder, onde o domínio do sujeito sobre uma determinada situação pode torná-lo incentivador e mediador de transformação de realidades sociais, tendo como foco, por exemplo, proporcionar o acesso e o uso da informação de forma consciente, impulsionando os sujeitos a conquistar seu espaço social, retirando-os da categoria de meros espectadores da realidade dos fatos.

0 sujeito, que se dispuser a participar destas mudanças e enxergar a necessidade de compartilhar suas experiências, utilizando sua capacidade cognitiva para transformar seu contexto social, estará trilhando o caminho do empoderamento, um conceito que segundo Borges e Holanda (2014), está associado à 'construção de capacidades' e a processos participativos.

Nesta perspectiva, apresentamos neste artigo os resultados de pesquisa realizada no âmbito do Programa Institucional de Bolsas de Iniciação Científica da Universidade Federal do Ceará (PIBIC/UFC) realizada com os bibliotecários que atuam no setor de referência de duas bibliotecas desta universidade. Tal pesquisa visou investigar se esses profissionais apresentam características de empoderados e protagonistas sociais no que concerne ao estágio do trabalho.

\section{EMPODERAMENTO E O PROTAGONISMO SOCIAL}

Quando o indivíduo se mobiliza dentro da sua realidade social, adquirindo novas formas de enxergar as perspectivas de uma construção de realidade, o empoderamento se torna uma multiplicação de ideias transformadoras. Esse indivíduo deve enxergar na conduta de sua ação um potencial enriquecedor de novos fluxos de ideias, que conduzem a uma libertação da sua consciência sendo capaz de se tornar um agente social. Essa reflexão é corroborada por Baquero (2012, p. 183) ao afirmar que o processo de empoderamento vai além do que trabalhar em nível conceitual, "envolve o agir, implicando processos de reflexão sobre a ação, visando a uma tomada de consciência a respeito de fatores de diferentes ordens [...] que conformam a realidade, incidindo sobre o sujeito." 0 empoderamento deve ser capaz de fazer com que as relações, sejam elas individuais ou coletivas, se tornem um elo entre os acontecimentos sociais e a esfera pública, onde a participação de todos possa se desdobrar em resultados que influenciem nas melhorias dos aspectos relevantes para a sociedade.

Segundo Kleba e Wendausen (2009, p. 738) há três níveis de empoderamento baseados nas interações interpessoais: pessoal ou psicológico, grupal ou organizacional e estrutural ou político; no nível psicológico "a unidade de análise são os indivíduos. Um dos aspectos centrais desse nível é a mudança de mentalidade a partir da percepção do sujeito das próprias forças, que resulta em um comportamento de autoconfiança."

No nível organizacional o empoderamento é gerado na e pela organização, conforme Baquero (2012, p. 177) "trata-se de uma abordagem do processo de trabalho que objetiva a delegação do poder de decisão, autonomia e participação dos funcionários e na administração das empresas, de modo que as decisões sejam mais coletivas e horizontais." Já o nível estrutural ou político "aplica os fundamentos éticos de justiça social e da redução de iniquidades que requerem transformações estruturais." (KLEBA; WENDAUSEN, 2009, p. 741). Os indivíduos precisam contextualizar suas ações tendo uma participação maior nas questões que envolvem 
grandes tomadas de decisões sejam elas políticas, econômicas ou sociais para que haja uma forma de se apropriarem da realidade em que estão inseridos. As ações precisam ser pautadas na busca por soluções para problemas que afetam não só sua vida, mas a vida de outros indivíduos que interagem com eles.

Quando a busca por estas soluções não consegue responder aos questionamentos que as situações oferecem, se faz necessário o uso de ferramentas que possam suprir essas deficiências. Estas ferramentas podem ser desde um curso de capacitação para a melhoria do seu desempenho no mercado de trabalho, ou até mesmo uma graduação de nível superior que resulte na ampliação da formação escolar.

O conhecimento sobre si mesmo e as capacidades cognitivas de aprendizagem ajudam na busca de uma melhor compreensão dos fatos. Quando o sujeito desenvolve a consciência de que sua atuação é fundamental para que as transformações da realidade social ocorram, poderá modificar a estrutura de convivência com outros indivíduos ou até mesmo as situações que exigem iniciativas na busca de soluções viáveis para essas questões.

Por isso, como ressaltam Villacorta e Rodriguez (2002, p. 50), as diversas experiências sobre o empoderamento demonstram que este não pode ser desenvolvido em nome daqueles que devem ser empoderados. Ainda conforme os autores, "[...] os processos de empoderamento devem centrar-se necessariamente nas pessoas e grupos desempoderados, em suas visões, interesses e prioridades [...]", com foco nas mudanças na consciência e na autopercepção, assim como o desenvolvimento de competências, tanto pessoais quanto coletivas.

Portanto, é necessário que o sujeito perceba que seu papel na sociedade é primordial para a prática de cidadania, levando a interferência em situações, em que ele se empodera de seus conhecimentos para aplicações de soluções úteis. A gerência dessas soluções precisa partir dos conhecimentos internos do sujeito, ou seja, daquilo que ele adquiriu ao longo de sua vida que acabou modificando sua forma de agir. Mas esse processo nem sempre é tão simples, pois ele pode se deparar com situações em que o uso dos seus conhecimentos adquiridos, não se transformem em habilidades, por não conseguir refletir sobre esses conhecimentos, isto é, se aprende algo, mas não se utiliza, e não se reflete sobre o aprendizado.

Diante disso, é necessário que o sujeito desenvolva seu empoderamento individual, para que suas ações sejam conduzidas pelo agir e pensar em estratégias de gerenciar os conflitos que são apresentados nas mais diversas situações. No empoderamento individual, o sujeito adquire o poder de julgar quais ações serão necessárias para que ele consiga tomar decisões, baseadas em suas vivências anteriores, e como essas ações podem beneficiar outros indivíduos.

Em se tratando de convívio em sociedade, os indivíduos constroem seus papéis sociais nas relações com outros indivíduos, as quais podem desencadear mudanças de comportamento e de autonomia. De alguma forma, quando há interação com as questões sociais, o indivíduo constrói novos caminhos para a elaboração de seu papel na sociedade, pois ele consegue transpor as barreiras que o mantém distante dos acontecimentos em seu meio, assim os resultados destas ações podem levá-lo ao protagonismo social. Conforme Farias (2015) atingir o protagonismo social é se tornar um sujeito na plenitude, é participar ativamente de processos decisórios, é consumir e produzir, ser mediador e mediado de práticas sociais.

O protagonismo social tende a colocar o sujeito como o principal transformador de sua própria realidade social. Ele exerce certa influência nas tomadas de decisões que possam auxiliar um indivíduo ou uma comunidade. Nesta perspectiva, aquele que é protagonista também tem sua própria realidade transformada. 
O protagonismo social está relacionado ao ato de empoderar, que é transformar a si mesmo e aos outros em protagonistas, é sair de uma condição de sujeição, é livrar-se do fardo de estar sujeito a uma subjetividade imposta que dita quem você é e como deve agir, é um processo criativo pelo qual pessoas e coletividades ampliam seu campo de ação. (ABEN, 2014, p. 16).

Consciente de seu papel social e do quanto ele pode desempenhar mudanças na sociedade, o protagonista busca fomentar ideias que visam reconhecer em outros indivíduos, a capacidade de darem respostas aos desafios que se manifestam em seu cotidiano. É o que pode ocorrer com o bibliotecário de referência, ao se deparar com situações que vão exigir desde habilidades interpessoais até habilidades técnicas que influenciam no atendimento ao usuário.

0 retorno que o usuário dá ao bibliotecário de referência pode também indicar quais mudanças são necessárias para que o processo de entrevista, que ocorre no setor de referência, seja mais simples e ao mesmo tempo mais dinâmico, já que um dos objetivos é tentar solucionar as dúvidas em relação aos serviços da biblioteca. Agindo como um protagonista social no trabalho, o bibliotecário de referência incorpora as necessidades informacionais dos usuários como sendo suas próprias necessidades, exercendo uma profícua interlocução e transformando as dificuldades de se comunicar com os usuários, em ações que refletem o papel deste profissional na sociedade.

\section{BIBLIOTECÁRIO DE REFERÊNCIA}

No contexto acadêmico, a biblioteca universitária atua como mediadora da informação, consolidando seu papel de difusora do conhecimento, transformando as mais diversas realidades que permeiam a sociedade e que necessitam de uma visão pautada na busca do reconhecimento social do indivíduo. Um destes indivíduos que possui um papel social relevante para a biblioteca universitária, é o bibliotecário do setor de referência, o qual pode contribuir na formação do senso crítico do usuário.

Houve um tempo, em que os bibliotecários eram tidos apenas como meros reprodutores de procedimentos no atendimento ao usuário ou como organizadores de fontes de informação, no entanto essa imagem vem mudando ao longo dos anos, pois as funções e atuações desse profissional devem acompanhar o ritmo acelerado das demandas informacionais da atual sociedade. As atribuições do bibliotecário, como a classificação do conhecimento humano, exercem relevante influência nas questões sociais que envolvem aspectos éticos, econômicos e políticos, pois dependendo de onde ele possa atuar será necessária uma adequação das necessidades informacionais dos seus usuários.

Os bibliotecários foram categorizados de acordo com as funções do setor em que ele atua, exercendo assim uma forma de fazer com que uma unidade de informação possa analisar quais atividades se encaixam melhor a cada perfil de bibliotecário. 0 bibliotecário de catalogação, por exemplo, exerce a função de organizar os objetos informacionais através de uma classificação utilizada de acordo com a demanda da unidade de informação.

Já o bibliotecário de referência surgiu como um facilitador na disseminação de informações, auxiliando nas dúvidas dos usuários em relação ao acervo da biblioteca, assim como também na orientação sobre os serviços que são ofertados nas unidades de informação. Em se tratando, por exemplo, de uma biblioteca universitária, as exigências para atender a comunidade acadêmica requer ainda mais competências desse profissional, pois em sua dinamicidade, como explicam Machado e Blattman (2011, p. 10), a biblioteca universitária apoia o ensino, a pesquisa e a extensão, ao prestar serviços aos alunos de graduação, pós-graduação, 
professores e funcionários, além de "promover a cooperação e o intercâmbio de ideias e conhecimentos científicos com outras bibliotecas e sociedade em geral". 0 bibliotecário que atua no setor de referência tem contato direto com o usuário. É ele quem possibilita:

[...] por meio do tratamento, organização, armazenamento, disseminação e uso da informação e/ou conhecimento atualizados, em qualquer formato, a satisfação das necessidades informacionais para o uso correto das tecnologias digitais, no intuito de contribuir para o desenvolvimento da ciência e tecnologia, na sociedade digital. (RIBEIRO; VETTER, 2008, p. 13).

Com tantas questões que envolvem a dinâmica de uma biblioteca, na prática diária do bibliotecário do setor de referência, isso significa dizer que esse profissional deve se preocupar e estar atento às demandas dos usuários, para o uso da informação de maneira mais consciente. Durante sua prática laboral, esse profissional ao atuar como um protagonista, principalmente no momento da entrevista, deve procurar responder/atender, conforme Grogan (1995), as questões dos usuários, sejam elas de caráter administrativo e orientação espacial, questões referentes a consultas sobre autor/título bem como a consultas de localização de fatos.

Em razão disto, as habilidades do bibliotecário de referência devem estar voltadas, principalmente, para o comportamento do usuário, desde o atendimento a busca de livros até reclamações sobre os serviços e produtos de informação que são oferecidos pela biblioteca. Neste contexto, segundo Borges e Oliveira (2010), esses profissionais atuam em espaços onde as interações sociais e os fluxos de informação são sempre constantes. Destarte, para atingir qualidade dos serviços oferecidos, o bibliotecário de referência deve se manter constantemente atualizado, devendo conhecer as necessidades políticas, econômicas, sociais e culturais do grupo no qual está inserido.

O bibliotecário de referência ao se empoderar dos processos que envolvem suas atividades profissionais, pode ajudar aos usuários ao apontar soluções que possibilitem aos mesmos uma participação na sociedade de forma mais crítica e mais ativa, motivando-os a romper com as barreiras que os colocam no papel de meros coadjuvantes de situações cotidianas, como o não acesso à informação ou até mesmo aos seus direitos. Essa atuação do bibliotecário junto aos usuários torna-o protagonista social.

\section{CAMINHOS METODOLÓGICOS}

Esta pesquisa desenvolveu-se a partir dos pressupostos metodológicos da abordagem qualitativa, pois este tipo de pesquisa não tenta aplicar conceitos préexistentes, e os instrumentos e técnicas de pesquisa são elaborados a partir do que o pesquisador sente ao conhecer o campo onde irá atuar, assim como os sujeitos e a realidade que os cerca. Já o método escolhido foi a pesquisa participante, a qual procura, conforme Le Boterf (1984, p. 52), “[...] auxiliar a população envolvida a identificar por si mesma os seus problemas, a realizar a análise crítica destes e a buscar as soluções adequadas. " Dessa forma, a seleção dos problemas estudados não surgiu apenas da decisão dos pesquisadores, mas sim dos sujeitos envolvidos

Os dados foram coletados por meio dos seguintes instrumentos: formulários de prospecção, questionários e roteiros de entrevista, os quais serviram para averiguar se os bibliotecários sujeitos da pesquisa apresentam características que se pode reconhecer como sendo empoderados e protagonistas sociais no que concerne ao estágio do trabalho. Esses dados foram analisados pela técnica análise do conteúdo de Bardin (2009), com estabelecimento de categorias. Esta técnica se 
constitui como um conjunto de instrumentos metodológicos em "[...] constante aperfeiçoamento, que se aplicam a 'discursos' diversificados". E por oscilar entre o rigor da objetividade e da fecundidade da subjetividade, atraindo o investigador pelo escondido, "[...] o latente, o não aparente, o potencial de inédito [...], redito por qualquer mensagem." (BARDIN, 2009, p. 11).

As duas bibliotecas escolhidas como campo de pesquisa, uma considerada de grande porte (com cinco bibliotecários que atuam exclusivamente no setor de referência, denominados na pesquisa de E1, E2, E3, E4 e E5) e outra de pequeno porte (com dois bibliotecários que trabalham em todos os setores, denominados E6 e E7), ofertam os seguintes serviços de informação: comutação bibliográfica, acesso livre à internet, consulta local, emissão de nada consta, ficha catalográfica, normalização de trabalhos acadêmicos, treinamento de usuários, novas aquisições, orientação sobre o uso da biblioteca e do acervo, catálogo online, renovação e reserva online e Pergamum mobile.

A partir dos dados coletados e analisados, construiu-se o perfil entrevistados, o qual se constitui de sete bibliotecários. Conforme Quadro 1, nota-se que a maioria dos entrevistados é do sexo feminino, e que a idade dos bibliotecários varia de 22 a 55 anos, sendo que a maior parte dos bibliotecários têm entre 25 e 32 anos. Além disso, observa-se que todos os entrevistados possuem pós-graduação, seja em nível latu sensu ou stricto sensu, sendo que três já são mestres e um está cursando doutorado, o que evidencia a preocupação com a educação continuada destes profissionais que têm contato direto com o usuário oferecendo produtos e serviços de informação.

Quadro 1: Perfil dos entrevistados.

\begin{tabular}{|c|c|c|c|c|c|}
\hline Entrevistado & Idade & Sexo & $\begin{array}{c}\text { Tempo de } \\
\text { trabalho na } \\
\text { UFC } \\
\end{array}$ & $\begin{array}{l}\text { Grau de } \\
\text { instrução }\end{array}$ & $\begin{array}{c}\text { Ano de } \\
\text { graduação }\end{array}$ \\
\hline E1 & 30 anos & Masculino & Oito anos & $\begin{array}{l}\text { Doutorado em } \\
\text { andamento }\end{array}$ & 2008 \\
\hline E2 & 55 anos & Feminino & $\begin{array}{c}30 \text { anos (16 } \\
\text { anos no setor } \\
\text { de referência) }\end{array}$ & Mestrado & 1985 \\
\hline E3 & 25 anos & Feminino & 3 meses & Especialização & 2012 \\
\hline E4 & 26 anos & Masculino & 2 anos & Graduado & 2012 \\
\hline E5 & 32 anos & Feminino & $\begin{array}{c}4 \text { anos (dois } \\
\text { meses no setor } \\
\text { de referência) }\end{array}$ & Mestrado & 2006 \\
\hline E6 & 31 anos & Feminino & 2 anos & Especialização & 2009 \\
\hline E7 & 53 anos & Feminino & 23 anos & Mestrado & 1991 \\
\hline
\end{tabular}

Fonte: Dados da pesquisa, 2016.

Ainda de acordo com o perfil acima, analisa-se que a maioria dos entrevistados trabalha há mais de dois anos na UFC, sendo que um há 30 anos e outro há 23 anos, o que demonstra que há um quadro de bibliotecários experientes nas bibliotecas pesquisadas. Observa-se também que a maior parte dos bibliotecários teve outras experiências profissionais antes iniciar a carreira na UFC, quais sejam: núcleo de documentação; projeto de educação curricular; biblioteca escolar; biblioteca universitária privada; e escola filantrópica. Atuar em distintas unidades de informação pode ter proporcionado a esses profissionais, a compreensão de quão relevante é sua relação com o usuário, o que é primordial para que o setor de referência funcione em sua plenitude.

Após apresentar o perfil dos bibliotecários entrevistados, discorre-se sobre os dados coletados e analisados a partir da técnica de análise de conteúdo. 


\section{ANÁLISE E DISCUSSÃO DOS RESULTADOS}

Construiu-se a trajetória desta pesquisa, com o objetivo de analisar se os bibliotecários que atuam no setor de referência apresentam indícios de empoderamento e estágios do protagonismo social no seu labor, mecanismos que podem colaborar com o desenvolvimento de estratégias que levem o bibliotecário a uma maior participação nas questões sociais, relativas à sua profissão, interação e comunicação com os usuários.

Para tal estabeleceu-se as seguintes categorias de análise: necessidades informacionais do usuário; atitude em relação às demandas informacionais específicas; recursos informacionais e critérios utilizados durante a pesquisa; pesquisa bibliográfica para seleção de informações; e utilização de múltiplos saberes em contextos diversos.

$\mathrm{Na}$ categoria necessidades informacionais do usuário (Quadro 2) objetivou-se observar como o bibliotecário dialoga com o usuário para determinar a real necessidade de informação, procurando selecionar e explorar diversas fontes de informação em suporte tradicional e digital, identificando termos que possam descrever a informação necessitada e localizando fontes solicitadas e outras que contemplem a informação desejada.

Os dados coletados demonstram que todos os bibliotecários entrevistados dialogam com o usuário para determinar a real necessidade de informação, sendo que $42,85 \%$ faz isso frequentemente, e $57,15 \%$ destes profissionais afirmam fazê-lo sempre. Isso demonstra que o bibliotecário tem consciência da necessidade de interagir com o usuário, e que seu trabalho deve configurar-se como uma tarefa de mediação, de filtragem e de elo no processo de apropriação de novos conhecimentos, o que requer qualificações diferenciadas e constante evolução, como afirma Oddone (1998). Por isso, o bibliotecário do setor de referência deve voltar sua atenção ao usuário no momento da busca, para atendê-lo de forma eficiente e eficaz, satisfazendo-o e instigando-o a buscar cada vez mais, se informando e absorvendo conhecimento.

Quadro 2: Necessidades informacionais do usuário.

\begin{tabular}{|c|c|c|c|c|c|}
\hline $\begin{array}{l}\text { Necessidade informacional } \\
\text { do usuário }\end{array}$ & Nunca & Raramente & Às vezes & Frequentemente & Sempre \\
\hline $\begin{array}{l}\text { Dialoga com o usuário para } \\
\text { determinar a real } \\
\text { necessidade de informação. }\end{array}$ & - & - & - & $\begin{array}{c}3 \\
(42,85 \%)\end{array}$ & $\begin{array}{c}4 \\
(57,15 \%)\end{array}$ \\
\hline $\begin{array}{c}\text { Seleciona e explora } \\
\text { diversas fontes de } \\
\text { informação em suporte } \\
\text { impresso e digital. }\end{array}$ & - & - & $1(14,28 \%)$ & $\begin{array}{c}4 \\
(57,15 \%)\end{array}$ & $\begin{array}{c}2 \\
(28,57 \%)\end{array}$ \\
\hline $\begin{array}{l}\text { Identifica termos que } \\
\text { possam descrever a } \\
\text { informação necessitada. }\end{array}$ & - & - & $\begin{array}{c}2 \\
(28,57 \%)\end{array}$ & $\begin{array}{c}2 \\
(28,57 \%)\end{array}$ & $\begin{array}{c}3 \\
(42,86 \%)\end{array}$ \\
\hline $\begin{array}{l}\text { Localiza fontes solicitadas e } \\
\text { outras que contemplem a } \\
\text { informação desejada. }\end{array}$ & - & $\begin{array}{c}1 \\
(14,28 \%)\end{array}$ & - & $\begin{array}{c}2 \\
(28,57 \%)\end{array}$ & $\begin{array}{c}4 \\
(57,15 \%)\end{array}$ \\
\hline
\end{tabular}

Fonte: Quadro adaptado de Santos (2015). Dados da pesquisa (2016).

No segundo questionamento desta categoria, a maioria $(85,72 \%)$ dos bibliotecários afirmou selecionar e explorar, frequentemente e sempre, diversas 
fontes de informação em suporte impresso e digital, e apenas um bibliotecário procede, às vezes, com estas ações. Deste modo, infere-se que os entrevistados procuram se empoderar das ferramentas de pesquisa e as utilizam em suas atividades laborais diárias durante o atendimento ao usuário. 0 que pode significar que a maioria dos entrevistados se encontra no nível de empoderamento individual, no qual, conforme, Kleba e Wendausen (2009), o sujeito adquire poder de julgar quais ações serão necessárias, para que ele consiga tomar decisões, baseadas em seus conhecimentos e como essas ações podem beneficiar outros indivíduos.

A maior parte dos bibliotecários (71,43\%) ressaltou que, frequentemente e sempre, procura identificar termos que descrevem a informação necessitada, sendo que um percentual de 28,57\% realiza esta ação apenas às vezes. Para Timbó (2002), o bibliotecário de referência deve auxiliar aos usuários em quaisquer tipos de questões, sejam elas bem elaboradas ou ainda a serem lapidadas, tarefa em que o profissional deve ser perito.

Em relação a localizar fontes solicitadas pelos usuários e outras que contemplem a informação desejada, somente um bibliotecário afirmou que raramente realiza este procedimento. Isso evidencia a necessidade de o bibliotecário de referência compreender que deve agir de modo democrático, como afirma Timbó (2002, p. 87), para que possa fornecer mais de uma resposta possível para a questão, oferecendo várias fontes e propiciando que o usuário decida sem imposição ao modo de pensar do bibliotecário. "Em momento algum o bibliotecário deve sugerir que o usuário use esse ou aquele texto. 0 usuário é quem pode dar a última palavra na seleção do material que possa atender sua necessidade naquele momento".

A categoria atitude em relação às demandas informacionais específicas (Quadro 3) trata da forma como o bibliotecário se posiciona em relação às demandas de informações provenientes de grupos de usuários com interesses específicos. Se há iniciativas e atitudes deste profissional, a exemplo de analisar a questão de pesquisa inicial do grupo, a fim de verificar a possibilidade de inserção de dados à pergunta ou até mesmo descartar informações que o profissional considera como irrelevantes.

Quadro 3: Atitude em relação a demandas informacionais específicas.

\begin{tabular}{|c|c|c|c|c|c|}
\hline $\begin{array}{l}\text { Atitude em relação a } \\
\text { pesquisas para atender } \\
\text { uma demanda de um grupo } \\
\text { de usuários }\end{array}$ & Nunca & Raramente & Às vezes & Frequentemente & Sempre \\
\hline $\begin{array}{l}\text { Analisa a questão de } \\
\text { pesquisa inicial do grupo, a } \\
\text { fim de verificar a } \\
\text { possibilidade de inserção } \\
\text { de dados à pergunta. }\end{array}$ & - & - & $\begin{array}{c}1 \\
(14,28 \%)\end{array}$ & $\begin{array}{c}5 \\
(71,42 \%)\end{array}$ & $\begin{array}{c}1 \\
(14,28 \%)\end{array}$ \\
\hline $\begin{array}{l}\text { Descarta informações que } \\
\text { considera irrelevantes. }\end{array}$ & - & $\begin{array}{c}2 \\
(28,57 \%)\end{array}$ & $\begin{array}{c}3 \\
(42,85 \%)\end{array}$ & $\begin{array}{c}1 \\
(14,28 \%)\end{array}$ & $\begin{array}{c}1 \\
(14,28 \%)\end{array}$ \\
\hline $\begin{array}{lr}\text { Procura } & \text { sugerir } \\
\text { informações } & \text { adicionais } \\
\text { resultantes de pesquisas. }\end{array}$ & - & - & $\begin{array}{c}2 \\
(28,57 \%)\end{array}$ & $\begin{array}{c}4 \\
(57,15 \%)\end{array}$ & $\begin{array}{c}1 \\
(14,28 \%)\end{array}$ \\
\hline
\end{tabular}

Fonte: Quadro adaptado de Santos (2015). Dados da pesquisa (2016).

A maioria dos entrevistados $(85,7 \%)$ analisa, frequentemente e sempre, a questão de pesquisa inicial do grupo, para poder verificar a possibilidade de inserção de dados à pergunta. Infere-se que esses bibliotecários colocam em prática os ensinamentos de disciplinas como Serviços de Informação, na qual se estuda o processo de entrevista no serviço de referência descritos por Grogan (1995). De 
acordo com esse autor, o terceiro e quarto passos são respectivamente: a 'questão inicial', no qual o usuário formula a questão e solicita auxílio do bibliotecário; e a 'questão negociada', onde o bibliotecário solicita esclarecimentos sobre a questão inicial para atender satisfatoriamente a necessidade do usuário. Nessas duas fases, o bibliotecário deve estar atento à possibilidade de o usuário ter dúvidas em relação à pesquisa solicitada, por isso é primordial ter atenção ao que realmente o usuário deseja, sendo necessário por vezes, que os bibliotecários refaçam com os usuários o primeiro e segundo passos, delineados por Grogan (1995), quais sejam: 'o problema' e 'a necessidade de informação'. Esses passos acontecem com objetivo de se chegar ao oitavo denominado de 'a solução', o qual prevê que o bibliotecário e o usuário devem avaliar se o resultado obtido é suficiente para finalizar o processo de busca.

Ainda em relação à relevância deste momento da entrevista, Timbó (2002), ressalta que a fase inicial do processo de referência se constitui no compartilhamento da questão do usuário com o bibliotecário, e para isso, esse profissional deve considerar a questão do usuário como sendo sua, para que a busca ocorra com entusiasmo.

Neste contexto, percebe-se que há indícios de protagonismo social no que concerne ao estágio trabalho, o qual pode ser detectado na maioria dos entrevistados (71,43\%), ao sugerirem aos usuários informações adicionais resultantes das pesquisas. Esse resultado conduz ao pensamento de que os bibliotecários estão atentos ao que o usuário deseja e, por isso, procuram satisfazêlo, conquistando-o com um serviço de referência pleno, demonstrando autonomia e características do conceito de alteridade, de pensar no outro e nele se vê.

Em relação ao descarte de informações consideradas irrelevantes, as respostas evidenciam que apenas $28,56 \%$ descartam este tipo de informação frequentemente e sempre. Esse dado leva à reflexão de que, talvez diante das diversas demandas solicitadas diariamente ao bibliotecário, o filtro de seleção de informações possa ocorrer de forma mecanizada, deixando assim passar o que seria considerado como irrelevante.

A categoria recursos informacionais e critérios utilizados durante a pesquisa (Gráfico 1 e 2) estabelece quais recursos e critérios de pesquisa são comumente utilizados durante a pesquisa e para orientar o usuário.

Conforme os dados coletados (Gráfico 1), a maioria dos entrevistados respondeu que utiliza, principalmente, as seguintes fontes de informação durante a pesquisa: biblioteca digital ou virtual, biblioteca física, bases de dados com textos ou referenciais, livros, teses, dissertações, trabalhos de conclusão de curso, revistas científicas, repositórios institucionais, colegas, anais de evento científicos e até mesmo o Google. A Wikipédia e o Comut foram citados por 57,15\% dos bibliotecários como recursos informacionais utilizados no cotidiano.

Observa-se que grande parte das fontes escolhidas como instrumentos de pesquisa no dia a dia dos entrevistados, se constitui em fontes de informação científica e tecnológica de caráter formal. Conforme Cunha (2001), o uso efetivo desse tipo de fonte ajuda a evitar a duplicação de trabalhos previamente realizados, uma ação que pode servir como inspiração para os usuários. 


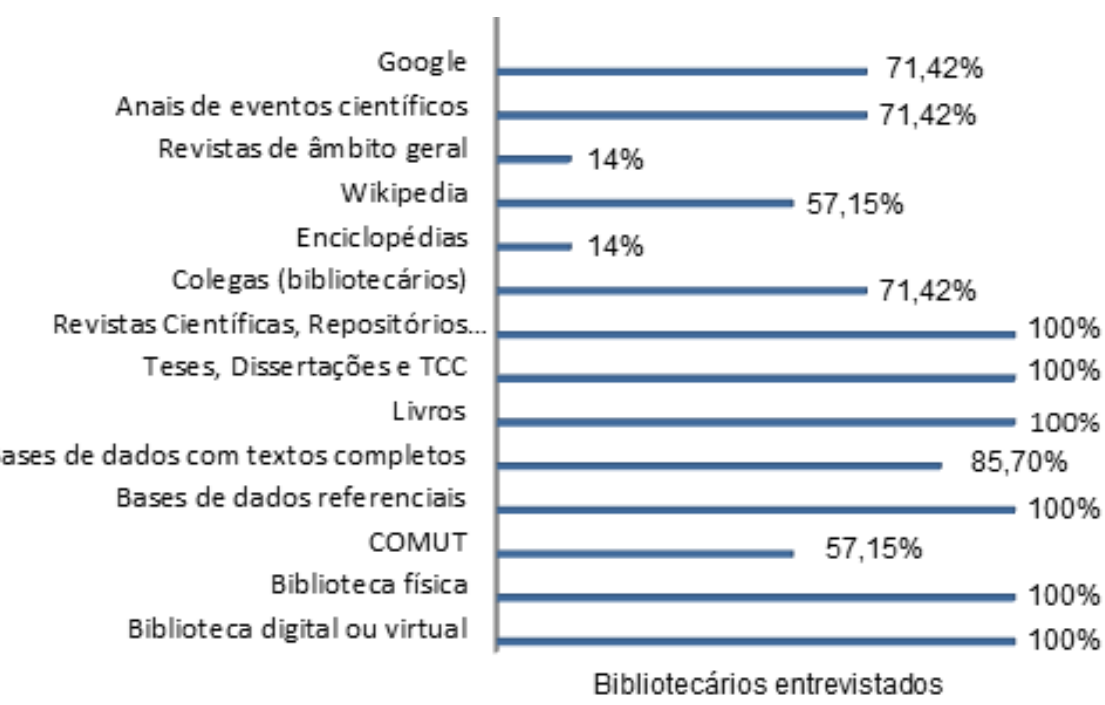

Gráfico 1: Recursos informacionais na pesquisa.

Fonte: Dados da pesquisa, 2016.

Ainda ficou em evidência que apenas 14\% dos bibliotecários utilizam enciclopédias e revistas de âmbito geral. No caso das enciclopédias, uma explicação para esse índice de utilização, se deve ao fato de que necessitam de um período maior para serem atualizadas, se comparadas a outras fontes. Já em relação às revistas de âmbito geral, pode-se inferir que a baixa utilização por parte dos entrevistados, está no fato de talvez não serem consideradas como fontes de informação científica, como se configuram as revistas científicas, as quais são revisadas por pares, o que confere confiabilidade e qualidade às publicações.

Em relação aos critérios mais utilizados durante uma pesquisa (Gráfico 2) foram mencionados pela metade dos bibliotecários a busca avançada para recuperar a informação. Além disso, foram mencionados em segundo lugar os operadores booleanos (42\%) e em terceiro o truncamento (8\%). Nenhum dos entrevistados respondeu que utiliza os operadores de proximidade.
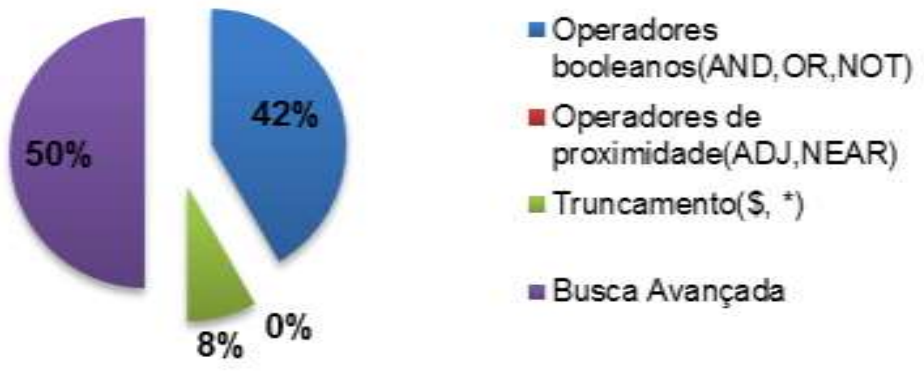

Gráfico 2: Critérios mais utilizados em uma pesquisa.

Fonte: Dados da pesquisa, 2016.

Isso pode ocorrer, devido aos operadores booleanos e a busca avançada serem mais utilizados em sistemas de recuperação da informação, a fim de facilitar a compreensão do usuário, o que explicaria também a adoção destes critérios por parte dos bibliotecários.

A categoria pesquisa bibliográfica para seleção de informações verifica como o bibliotecário utiliza o recurso de pesquisa bibliográfica para atender a uma demanda informacional do usuário (Quadro 4). Por exemplo, se ele sempre retoma a pergunta da pesquisa original procurando determinar se são necessárias informações adicionais ou até mesmo a reformulação da pergunta, ou ainda se ele 
revisa os resultados iniciais da pesquisa e em busca de compreender todas as informações levantadas.

Esse procedimento investigativo por parte dos bibliotecários se faz necessário para tentar obter o máximo de informações do usuário, visando atender suas necessidades. Conforme Sousa (2009, p. 31), "o caráter investigativo deve nortear o trabalho deste profissional, não devendo estar preso apenas a questões mecânicas e técnicas. Ele deve também assumir o papel de pesquisador."

Quadro 4: Pesquisa bibliográfica para seleção de informações.

\begin{tabular}{|c|c|c|c|c|c|}
\hline $\begin{array}{l}\text { Pesquisa bibliográfica para } \\
\text { atender a uma demanda } \\
\text { informacional }\end{array}$ & Nunca & Raramente & Às vezes & Frequentemente & Sempre \\
\hline $\begin{array}{l}\text { Revisa as perguntas da pesquisa } \\
\text { original para determinar se são } \\
\text { necessárias informações } \\
\text { adicionais ou reformulação. }\end{array}$ & - & - & $\begin{array}{c}2 \\
(28,57 \%)\end{array}$ & $\begin{array}{c}2 \\
(28,57 \%)\end{array}$ & $\begin{array}{c}3 \\
(42,85 \%)\end{array}$ \\
\hline $\begin{array}{l}\text { Analisa os resultados iniciais da } \\
\text { pesquisa. }\end{array}$ & - & $\begin{array}{c}1 \\
(14,28 \%)\end{array}$ & $\begin{array}{c}1 \\
(14,28 \%)\end{array}$ & $\begin{array}{c}3 \\
(42,85 \%)\end{array}$ & $\begin{array}{c}2 \\
(28,57 \%)\end{array}$ \\
\hline $\begin{array}{l}\text { Procura compreender todas as } \\
\text { informações levantadas. }\end{array}$ & - & $\begin{array}{c}1 \\
(14,28 \%)\end{array}$ & $\begin{array}{c}1 \\
(14,28 \%)\end{array}$ & $\begin{array}{c}4 \\
(57,15 \%)\end{array}$ & $\begin{array}{c}1 \\
(14,28 \%)\end{array}$ \\
\hline $\begin{array}{l}\text { Verifica a pertinência da } \\
\text { informação para atender a uma } \\
\text { demanda. }\end{array}$ & - & - & - & $\begin{array}{c}3 \\
(42,85 \%)\end{array}$ & $\begin{array}{c}4 \\
(57,15 \%)\end{array}$ \\
\hline
\end{tabular}

Fonte: Quadro adaptado de Santos (2015). Dados da pesquisa (2016).

A maioria $(71,42 \%)$ dos entrevistados, conforme o quadro 4 , garantiu que analisa os resultados iniciais da pesquisa e procura compreender todas as informações recuperadas. Esse comportamento dos bibliotecários, sujeitos da pesquisa, mostra que esses profissionais compreendem o processo que constitui o serviço de referência, o qual requer ações que vão além de perguntas feitas por usuários e respostas dadas pelo bibliotecário do setor. Ao analisar os resultados de uma pesquisa, objetivando entender as informações levantadas, esse profissional está priorizando a assistência efetiva ao usuário, ao procurar fornecer não apenas uma resposta, mas uma solução, como já dito acima, esse seria o oitavo passo da entrevista de referência conforme Grogan (1995). Interessante seria saber o percurso que a informação obtida pelo usuário percorrerá após sair da biblioteca, em qual contexto ela seria utilizada, para produzir que tipo de conhecimento, talvez no futuro isso seja possível de ocorrer, no momento é algo utópico.

A categoria utilização de múltiplos saberes em contextos diversos (Quadro 5) trata da forma como o bibliotecário utiliza seus diversos conhecimentos a fim de elaborar produtos, serviços, projetos e ações, a exemplo de um projeto de intervenção na biblioteca.

Ao analisar os dados coletados, é possível observar que ao pensarem sobre a elaboração de projeto de intervenção na biblioteca, os entrevistados em sua maioria, responderam que apresentam uma reflexão da realidade de sua biblioteca, tendo como base a contribuição de diversos autores, referenciando-os. Entretanto, nenhum bibliotecário destacou utilizar apenas suas próprias opiniões. Percebe-se que existe um cuidado com as fontes a serem consultadas antes de produzir um projeto, e ainda há a preocupação em referenciar autores, não apresentando apenas seus próprios pensamentos, mesmo em se tratando de bibliotecários com muitos 
anos de experiência na área. Isso pode indicar o nível de consciência do bibliotecário, que efetivamente coloca em prática o que ele indica para o usuário, consultar e referenciar as fontes de informação formais. Ou seja, ele demonstra vivenciar o que propaga no seu ambiente de trabalho.

Quadro 5: Utilização de múltiplos saberes em contextos diversos.

\begin{tabular}{|l|c|c|c|c|c|c|c|}
\hline $\begin{array}{l}\text { Exemplo: elaboração de projeto de intervenção na } \\
\text { biblioteca E1 }\end{array}$ & E2 & E3 & E4 & E5 & E6 & E7 \\
\hline $\begin{array}{l}\text { Apresenta uma reflexão da realidade de sua } \\
\text { biblioteca, embasando-se, entretanto, nas } \\
\text { contribuições dos autores. }\end{array}$ & - & $\mathrm{X}$ & $\mathrm{X}$ & $\mathrm{X}$ & $\mathrm{X}$ & $\mathrm{X}$ \\
\hline $\begin{array}{l}\text { Utiliza ideias de diversos autores, referenciando- } \\
\text { os. }\end{array}$ & $\mathrm{X}$ & $\mathrm{X}$ & $\mathrm{X}$ & $\mathrm{X}$ & - & $\mathrm{X}$ & - \\
\hline Apresenta somente suas opiniões. & - & - & - & - & - & - & - \\
\hline
\end{tabular}

Fonte: Quadro adaptado de Santos (2015). Dados da pesquisa (2016).

Com base nos dados acima analisados, é possível identificar traços de empoderamento por parte dos bibliotecários entrevistados, pois conforme Hammerschmidt e Lenardt (2010, p. 361) empoderar envolve "[...] parceria e responsabilidade que cada ator social assume diante da vida, na acepção de tomar os rumos para influenciar no destino dos outros e de si próprio." Destarte, visualiza-se nos bibliotecários, sujeitos da pesquisa, indícios do empoderamento e do protagonismo social nas ações no setor de referência junto ao usuário, quais sejam: dialogar com o usuário a fim de determinar a real necessidade de informação, procurando selecionar e explorar fontes de informação seguras em diversos tipos de suporte, identificando termos que possam descrever a informação necessitada; ao analisar a questão de pesquisa inicial do usuário, visando inserir dados à pergunta $\mathrm{e}$ sugerindo aos usuários informações adicionais resultantes das pesquisas; e ainda ao avaliar os resultados iniciais da busca procurando compreender todas as informações levantadas.

Ficou evidente também, que os indícios do empoderamento e do protagonismo social podem ser potencializados, se os percentuais a seguir fossem alterados, pois $14,28 \%$ raramente localizam fontes solicitadas e outras que contemplem a informação desejada; $28,57 \%$ às vezes identificam termos que possam descrever a informação necessitada; esse mesmo percentual raramente descarta informações que considera irrelevante; e raramente e às vezes analisa os resultados iniciais da pesquisa e procura compreender todas as informações levantadas.

Com base nas respostas analisadas e de acordo com cada categoria, pode-se considerar que os bibliotecários de referência possuem habilidades que os caracterizam como protagonistas sociais nas bibliotecas em que atuam. Também ficou evidente que a maioria busca sempre se aperfeiçoar em sua área, para acompanhar as novas demandas informacionais dos usuários. Cabe salientar ainda, como base nos dados analisados, a consciência que estes bibliotecários demonstram ter de sua função social e de sua importância para a sociedade.

\section{CONSIDERAÇÕES FINAIS}

As bibliotecas universitárias se destacam no mundo acadêmico e na comunidade em geral, a partir do momento que buscam realizar ações que estimulem a pesquisa, o senso crítico e a autonomia dos usuários. Para tal, faz-se necessário a atuação do bibliotecário de referência que tem contato direto com o 
usuário, conhecendo suas dificuldades em lidar com as questões informacionais e com obstáculos em relação à busca pela informação.

Compreende-se que o bibliotecário de referência, pode exercer o empoderamento por meio das práticas biblioteconômicas aprendidas durante sua formação acadêmica. No entanto, cabe a ele buscar de fato, uma postura de reflexão social e política primeiramente para si, e, posteriormente para disseminar para o usuário, alcançando, dessa forma, o protagonismo social no que se refere ao estágio do trabalho.

As diversas situações que podem ocorrer em uma biblioteca universitária, demostram que o bibliotecário deve estar preparado para conciliar possíveis conflitos, que o usuário possa sentir em relação às buscas. Daí a importância de o bibliotecário de referência estar atualizado em relação às fontes informacionais que a biblioteca oferece e possa oferecer.

Desse modo, as práticas exercidas na biblioteca universitária, auxiliam o bibliotecário de referência a buscar estratégias que possam contemplar diversos perfis de usuários, nos mais variados serviços de informação, pois como demonstram os resultados da pesquisa, este profissional está cada vez mais atento a relevância de se empoderar não apenas das técnicas da profissão, mas de toda a complexidade humana e social que a cerca, percorrendo a trilha do protagonismo social, ao incorporar o papel de um agente/ator principal durante sua atuação junto aos usuários, bem como aos ainda não usuários, procurando atraí-los e conquista-los para a unidade de informação.

\section{AGRADECIMENTO}

Ao Programa Institucional de Bolsas de Iniciação Científica da Universidade Federal do Ceará (PIBIC/UFC).

\section{REFERÊNCIAS}

ABEN (Associação Brasileira de Enfermagem). Protagonismo da enfermagem no processo de cuidar. SEMANA BRASILEIRA DE ENFERMAGEM, 75. Caderno de Dicas, 2014. Brasília, (DF). Disponível em: <http://www.abennacional.org.br/download/dicas2014.pdf>. Acesso em: 20 Abr. 2016.

BAQUERO, Rute Vivian Angelo. Empoderamento: instrumento de emancipação social? - Uma discussão conceitual. Revista Debates, Porto Alegre, v. 6, n. 1, p.173-187, jan.-abr. 2012. Disponível em: <http://seer.ufrgs.br/index.php/debates/article/view/26722/17099>. Acesso em: 11 ago. 2015.

BARDIN, L. Análise de conteúdo. Tradução: Luís Antero reto e Augusto Pinheiro. Edição e revista atualizada. Lisboa: Edições 70, LDA, 2009.

BORGES, Eduardo César; OLIVEIRA, Nivaldo. O perfil do bibliotecário de referência do centro-oeste mineiro: a importância da qualificação profissional. In: SEMINÁRIO NACIONAL DE BIBLIOTECAS UNIVERSITÁRIAS, 16., 2010, Rio de Janeiro. Anais... Rio de Janeiro, 2010. p. 1-12. Disponível em: <http://repositorio.ufla.br/handle/1/317>. Acesso em: 11 ago. 2015.

CUNHA, Murilo Bastos da. Para saber mais: fontes de informação em ciência e tecnologia. Brasília: Briquet de Lemos/ Livros, 2001. 168 p.

FARIAS, Maria Giovanna Guedes. Mediação e competência em informação: proposições para a construção de um perfil de bibliotecário protagonista. InCID: Revista de Ciência da Informação e Documentação, Ribeirão Preto, v. 6, n. 2, p. 106-125, set./2015. 
GROGAN, Denis. A prática do serviço de referência. Brasília, DF: Briquet de Lemos, 1995.

HAMMERSCHMIDT, Karina Silveira de Almeida; LENARDT, Maria Helena. Tecnologia educacional inovadora para o empoderamento junto a idosos com diabetes mellitus. Texto e contexto - Enfermagem, Florianópolis, v. 19, n. 2, p. 358-365, Junho/2010. Disponível em: $<$ http://www.scielo.br/scielo.php?script=sci_arttext\&pid=S010407072010000200018\&lng=en\&nrm=iso >. Acesso em 28 Ago. 2015.

KLEBA, Maria Elisabeth; WENDAUSEN, Águeda. Empoderamento: processo de fortalecimento dos sujeitos nos espaços de participação social e democratização política. Saúde e Sociedade, São Paulo, v. 18, n. 4, p. 733-743, dez./2009 . Disponível em: <http://www.scielo.br/scielo.php?script=sci_arttext\&pid=S010412902009000400016\&lng=en\&nrm=iso>. Acesso em: 13 Ago. 2015

LE BOTERF, Guy. Pesquisa participante: propostas e reflexões metodológicas. In: BRANDÃO, Carlos Rodrigues. (Org.). Repensando a pesquisa participante. São Paulo: Editora Brasiliense, 1984. p. 51-81.

MACHADO, Marli; BLATTMANN, Úrsula. A biblioteca universitária e sua relação com o projeto pedagógico de um curso de graduação. Biblos: Revista do Instituto de Ciências Humanas e da Informação, v. 25, n. 1, p. 9-20, jan./jun. 2011. Disponível em: <https://www.seer.furg.br/biblos/article/viewFile/1993/1223>. Acesso em: 25 Ago.2015.

ODDONE, Nancy. 0 profissional da informação e a mediação dos processos cognitivos: a nova face de um antigo personagem. Informação e Sociedade: estudos, João Pessoa, v. 8, n. 1, 1998. Disponível em: <http://www.ies.ufpb.br/ojs/index.php/ies/article/view/425/346>. Acesso em: 05 out. 2015.

RIBEIRO, R. J. A.; VETTER, S, M. J. Perfil do Bibliotecário de referência em bibliotecas universitárias na sociedade digital. In: SEMINÁRIO NACIONAL DE BIBLIOTECAS UNIVERSITÁRIAS, 15, 2008. São Paulo. Anais...São Paulo: CRUESP, 2008.

SANTOS, Jaires Oliveira. Competência em informação dos egressos do curso de Biblioteconomia: uma análise na região Nordeste do Brasil. 142 f. Dissertação (Mestrado em Ciência da Informação) - Universidade Federal da Bahia, Instituto de Ciência da Informação, Salvador, 2015.

SOUSA, Margarida Maria de. A biblioteca universitária como ambiente de aprendizagem no ensino superior. 2009. 90 p. Dissertação (Mestrado em Cultura e Informação) Universidade de São Paulo, São Paulo, 2009.

TIMBÓ, Noeme Viana. 0 controle emocional do bibliotecário facilitando o processo de comunicação na entrevista de referência. Revista de Educação do Cogeime, São Paulo, n. 21, p. 83- 89, dez./2002. Disponível em: <http://www.cogeime.org.br/revista/cap0721.pdf>. Acesso em: 03 Jun. 2016.

VILLACORTA, Alberto Enrìquez; RODRÌGUEZ, Marcos. Metodologias e ferramentas para implementar estratégias de empoderamento. In: Empoderamento e direitos no combate à pobreza. Rio de Janeiro: ActionAid Brasil, 2002. p. 45-66. 